\title{
What Happened to Posteroventral Pallidotomy for Parkinson's Disease and Dystonia?
}

\author{
Robert E. Gross \\ Departments of Neurosurgery and Neurology, Emory University School of Medicine, Atlanta, Georgia 30022
}

\begin{abstract}
Summary: Fifteen years after its resurrection, pallidotomy for Parkinson's disease (PD) and dystonia has once again been supplanted, this time by deep brain stimulation (DBS). Did this occur because pallidotomy was not effective or safe, or because DBS was found to be more effective and safer? This review focuses on the evidence-and its quality-supporting the effectiveness and safety of pallidotomy for PD and dystonia, and the comparative effectiveness and safety of DBS of the subthalamic nucleus (STN) and globus pallidus pars interna (GPi). Discussed first are the determinants of "level 1" recommendations, including the confounding effects on interpretation of randomized clinical trials (RCTs) that fail to control for patient bias (i.e., placebo effects). Although several RCTs have been performed comparing unilateral pallidotomy to medical therapy, GPi DBS, or STN DBS for PD, none controlled for patient bias. Comparison of these trials to estimate the placebo effect,
\end{abstract}

and examination of retrospective case series, suggests that the true effectiveness of unilateral pallidotomy is $20 \%$ to $30 \%$ reduction of 'off' total motor UPDRS scores, which is similar to the effects of unilateral GPi DBS or STN DBS, but less than bilateral STN DBS. At experienced centers, safety of unilateral pallidotomy appears equivalent to unilateral DBS, but bilateral DBS is likely safer than bilateral pallidotomy. Whereas there have been no RCTs of pallidotomy for dystonia, two doubleblind, sham-controlled RCTs of bilateral GPi DBS were performed. Nevertheless, limited uncontrolled series suggest that bilateral pallidotomy is similar to GPi DBS in effectiveness and safety for dystonia. Thus, pallidotomy was not rejected because of lack of effectiveness or safety, and it remains a viable alternative in situations where DBS is not available or not feasible. Key Words: DBS, subthalamic nucleus, thalamus, globus pallidus.

\section{INTRODUCTION}

In 1983, Ronald R. Tasker and colleagues ${ }^{1}$ posed the question, "What happened to Vim thalamotomy for Parkinson's disease?", and presented data to show that thalamotomy was an effective operation that should not have been discarded. Nine years later, the seminal article on posteroventral pallidotomy by Laitinen et $\mathrm{al}^{2}$ helped usher in the renaissance of functional neurosurgery. Now, some 15 years later, is an appropriate time to reframe Tasker's question for the present situation: "What happened to posteroventral pallidotomy?"

In their introduction, Tasker et al. ${ }^{1}$ charted the upswing of stereotactic surgery for Parkinson's disease (PD) in terms of 16 publications in the Journal of Neurosurgery from 1961 to 1970, and its rapid demise (with

Address correspondence and reprint requests to: Robert E. Gross, M.D., Ph.D., Department of Neurosurgery, The Emory Clinic, Suite B6200, 1365 Clifton Road N.E., Atlanta, GA 30022. E-mail: robert. gross@emoryhealthcare.org. the advent of levodopa) in terms of three publications in that journal from 1971 to 1982 . Hariz ${ }^{3}$ continued this charting method, showing that by 2001 the number of publications on pallidotomy (28), which had surged after 1992, was again on the decline. Conversely, by 2001 the surge in publications on deep brain stimulation (DBS) (which began after a seminal publication on DBS for tremor in 1996, by Benabid et al. ${ }^{4}$ ) was just beginning to peak. Since then, the number of pallidotomy publications has continued to decline, dropping to four in 2007, of which only two involve PD. ${ }^{5,6}$ In contrast, the number of DBS publications has increased even more dramatically than chronicled by Hariz, ${ }^{3}$ peaking at 90 on PD alone in 2007.

Is pallidotomy for PD and dystonia dead, and if so, why? In discussing the future of DBS, Benabid ${ }^{4}$ has often remarked that "the best fate of a therapy is to be replaced by a better therapy" (personal communication). Was pallidotomy discarded because it was unsafe or ineffective, or was it replaced by a better therapy-that is, by DBS? 


\section{WHAT HAPPENED TO POSTEROVENTRAL PALLIDOTOMY FOR PD?}

\section{Pallidotomy: The prequel and the sequel}

Pallidotomy owes its origins, as well as its demise, to both science and serendipity. Russell Myers ${ }^{7,8}$ led the way, inspired by advances in understanding of the role of the basal ganglia in movement (science) and by his mentor Jefferson Browder's foray into the caudate nucleus in a parkinsonian patient in the 1930s (serendipity). Open (i.e., nonstereotactic) ablation of the caudate nucleus, the medial globus pallidus, or both was increasingly performed through the 1940s. (This history is reviewed by Guridi and Lozano. ${ }^{9}$ ) Independently and essentially in isolation, Hirotaro Narabayashi and Teruo Okuma ${ }^{10}$ began to perform pallidotomy in Japan, also motivated by increased pathophysiological understanding of the role of basal ganglia in PD. ${ }^{9}$ At approximately the same time, serendipity led I.S. Cooper ${ }^{11}$ (after his observation of improved parkinsonism upon ligation of the anterior choroidal artery in the course of an aborted open pedunculotomy) to begin to perform chemopallidotomy.

Thereafter, stereotactic pallidotomy began to be widely performed for PD, propelled by the advent of stereotactic techniques pioneered in large measure by Earnst A. Spiegel and Henry T. Wycis. ${ }^{12}$ Again science and serendipity played its hand. Cooper and colleagues ${ }^{13,14}$ abandoned pallidotomy in favor of thalamotomy when an autopsy revealed that a planned pallidotomy, in a patient who had experienced marked reduction in tremor after the surgery, inadvertently strayed to the thalamus. Independently, the anatomical studies of Rolf Hassler ${ }^{9,15}$ on the basal ganglia circuitry, inspired by the disappointing results of pallidotomy, led himself and others ${ }^{16}$ away from the pallidum and into the ventral lateral thalamus (ventralis oralis), where the striking effects on parkinsonian tremor of thalamotomy (and subthalamotomy, discussed separately) led to its popularity and concurrently the demise of pallidotomy. ${ }^{17}$

Thus, it was the robust effect of thalamotomy on parkinsonian tremor (which was likely the most striking early symptom of PD in the era before levodopa), rather than the advent of levodopa in the 1960s, that spelled the demise of the first era of pallidotomy. Nevertheless, during the initial years of levodopa treatment, when stereotactic surgery for PD was rarely performed (or at least rarely reported), some centers continued to perform pallidotomy. ${ }^{18}$ Just as levodopa arrived, Lars Leksell empirically observed that posteromedial and ventral lesions were more effective on all symptoms of PD than the originally targeted anteromedial and dorsal region of the globus pallidus pars interna (GPi). ${ }^{19}$

With this insight in mind, and the increasing appreciation of the limitations of levodopa therapy and its complications (e.g., dyskinesia), Lauri V. Laitinen revisited pallidotomy. He performed his first surgery in 1985, some 2 years after Tasker's visionary article. ${ }^{2,20}$ Yet again, science and empiricism overlapped. The excellent empirical results reported by Laitinen with posteroventral pallidotomy were contemporaneous with further advancement in the conceptual understanding of the fronto-striatal-pallido-thalamo-cortical circuitry. The research of DeLong et al., ${ }^{21,22}$ Albin et al., ${ }^{23}$ and others highlighted the parallel, segregated organization of the skeletomotor, oculomotor, limbic, and associative circuits and identified the sensorimotor circuits of the GPi in the posteroventrolateral region. Moreover, the beneficial effects of lesions in this region were demonstrated in nonhuman primates with experimental parkinsonism. ${ }^{24}$ The coincidence of these two advances (i.e., promising results in a small series of post-levodopa era PD patients, and greater understanding of the pathophysiology and anatomy of PD) generated considerable excitement among both neurosurgeons and neurologists driving the resurgence of surgical treatment of PD. What, then, led to the demise of posteroventral pallidotomy?

\section{Is posteroventral pallidotomy an effective operation for PD?}

Perhaps pallidotomy was replaced because it was an ineffective operation. The obvious question then is, what does the literature have to say on the effectiveness of pallidotomy? First, however, several points in regard to clinical trials of surgical treatments should be considered.

Confounds in positive findings from clinical trials. Randomized, controlled trials (RCTs), the source of the strongest clinical evidence regarding a therapeutic approach, ${ }^{25}$ are more challenging to accomplish in testing a surgical treatment than in testing a medication. Even more challenging is performing a double-blind RCT, the only study that truly controls for both observerand patient-related bias. Single-blind (observer-blind) RCTs do not control for patient-related bias (placebo effect), which in surgical trials requires a 'sham' or mock-surgery condition. Although this is relatively easy to achieve in trials of DBS, it presents ethical challenges (though not necessarily insurmountable ones) ${ }^{26,27}$ in most surgical trials, including those of pallidotomy. Hence, there has never been a double-blind sham-controlled RCT of pallidotomy, whereas there have been several single-blind (observer-blind) RCTs. The interpretability of the positive results of these studies is potentially confounded by false positive (type I) error, or the finding of an effect where none actually exists.

Confounds in negative findings from clinical trials. On the other hand, negative data can also be misleading. In an individual RCT negative results may arise from true treatment failure (i.e., the treatment really does not work), or evaluation failure. The latter reflects 
false-negative (type II) error, or failure to find an effect where one truly exists. Unfortunately, in the surgical fields, when it is very difficult to perform RCTs, undue weighting may be given to RCTs that are negative, which may in fact reflect evaluation failure due either to technically inadequate surgical procedures or to poor trial design (arguably the case with fetal cell transplantation). ${ }^{28,29}$ Thus, it is important to avoid assigning undue weighting to any individual surgical RCT of pallidotomy, which may underestimate treatment effects.

Meta-analyses. In recent years, meta-analyses have been performed to try to glean data by pooling studies with small sample sizes. However, this type of analysis is only as good as the data going into it. Whereas a metaanalysis of similar class 1 studies may be useful in compensating for false-negative (type II) error, it has been inappropriately used to draw conclusions from uncontrolled studies confounded by bias. ${ }^{30}$ (As the computer scientists have warned, 'garbage in, garbage out.'). For example, a meta-analysis of uncontrolled studies was inappropriately used to argue that microelectrode recording during pallidotomy is more risky than using macroelectrode stimulation alone. ${ }^{30,31}$

Posteroventral pallidotomy: The evidence. Observer bias can be removed in evaluating pallidotomy by using head coverings to cover visible evidence of surgery or by blinded videotaped evaluations (or both). ${ }^{32-36}$ In a prospective single-blind (observer-blind) study without a control group, Lozano et al. ${ }^{34}$ found a $30 \%$ benefit from baseline 'off' period total motor (part 3) scores on the Unified Parkinson's Disease Rating Scale (UPDRS) after unilateral pallidotomy, with blinded videotape evaluations to control for observer bias, whereas Ondo et al. ${ }^{36}$ found only a $13.6 \%$ benefit (Table 1). Recently, two single-blind (observer-blind) RCTs ${ }^{32,33}$ comparing unilateral pallidotomy to best medical therapy demonstrated $31 \%$ to $34 \%$ decrease in 'off' total motor UPDRS scores at 6 months, in contrast to $4 \%$ to $8 \%$ worsening in the control group. However, although these single-blind studies effectively controlled for observer bias, the fail- ure to eliminate the potential for patient bias is a major limitation in their interpretation.

Placebo effects have been well documented in PD patients. ${ }^{26,27,37}$ In a large clinical trial, placebo response was $20 \%$ to $30 \%$, and larger magnitude effects are seen based on extent of intervention. ${ }^{26,38}$ In an unpublished trial of porcine fetal cell transplantation, ${ }^{39}$ implanted patients sustained a benefit from surgery of similar magnitude to that of the sham-surgery control group, demonstrating the potential for a surgical placebo response in a setting in which patients can only guess at the group they are in. Even though no significant placebo response was found in the Freed et al. ${ }^{28}$ human fetal cell transplantation trial, there was a significant impact of guessing. ${ }^{40}$ Patients were queried before each evaluation as to which group - sham or transplant-they thought they were in. Remarkably, whether patients were in the sham or transplant group, if they thought they had received the transplant, they performed better on both subjective as well as rater-blind objective measures (e.g., UPDRS motor score). Thus, patients' perception that they are in the active treatment group, in the context of a lack of equipoise regarding the two treatments, can bias the results of even a double-blind, sham-controlled RCT.

What effect might patients' knowing which group they are in have on a single-blind (observer-blind) trial in which there is lack of patient equipoise? In the two single-blind RCTs of unilateral pallidotomy versus best medical therapy, where patients' lack of equipoise might have led them to think that pallidotomy was the desirable active group and medical therapy the undesirable control group (why else would they enroll in a surgical trial?), a $31 \%$ to $34 \%$ improvement at 6 months was observed (Table 1). In contrast, in a randomized single-blind (observer-blind) study comparing unilateral pallidotomy to bilateral STN DBS, ${ }^{41,42}$ in which it could be argued that lack of patient equipoise would disfavor the unilateral pallidotomy arm, pallidotomy led to a $20 \%$ decrease in 'off' total motor UPDRS scores at 6 months. A randomized but unblinded comparison of unilateral pallidotomy

TABLE 1. Controlled Trials of Pallidotomy

Change in 'off' Motor UPDRS, \%

\begin{tabular}{llcc} 
& \multicolumn{1}{c}{ Design } & Uni Palli & Control \\
\hline Lozano et al. $^{34}(1995)$ & Blinded videotape evaluation & -30 & none \\
Ondo et al. ${ }^{36}(1998)$ & Blinded videotape evaluation & -14 & none \\
Merello et al ${ }^{44}(1999)$ & Cohort control & -45 & +4 (med therapy) \\
de Bie et al ${ }^{32}(1999)$ & RCT; single (observer) blind & -31 & +8 (med therapy) \\
Vitek et al..$^{33}(2003)$ & RCT; single (observer) blind & -34 & +4 (med therapy) \\
Merello et al. ${ }^{43}(1999)$ & RCT; no blind & -30 & -29 (Uni GPi DBS) \\
Esselink et al. & & & \\
\end{tabular}

DBS = deep brain stimulation; GPi = globus pallidus pars interna; med therapy = best medical therapy; RCT = randomized controlled trial; STN = subthalamic nucleus; Uni Palli = unilateral pallidotomy; UPDRS = Unified Parkinson's Disease Rating Scale (Part 3-Motor). 
to unilateral GPi DBS ${ }^{43}$ showed a $29.7 \%$ improvement in 'off' total motor UPDRS scores in the pallidotomy group, compared with a $28.8 \%$ decrease in the DBS group. The same researchers, when comparing unilateral pallidotomy to medical therapy, ${ }^{44}$ again in an unblinded study, found a $45 \%$ improvement in the former, compared with a $4 \%$ worsening in the latter. These studies support the role of patient bias as a potential confound in single-blind (observer-blind) studies of pallidotomy, and suggest that the true unilateral pallidotomy effect is between $20 \%$ and $30 \%$ improvement in UPDRS motor score.

Longer follow-up periods can mitigate both potential placebo responses and temporary effects of suboptimal pallidotomy. ${ }^{38}$ Kishore et al. ${ }^{45}$ initially reported significant benefits at 6 months on all features of PD after unilateral pallidotomy, but by 24 months the only stable effects were on contralateral tremor and drug-induced dyskinesia. ${ }^{46}$ In the RCT reported by Vitek et al., ${ }^{33}$ the $34 \%$ decrease in the motor UPDRS score at 6 months waned to a $25 \%$ decrease at 24 months, similar to the $21 \%$ decrease found by the Toronto group at 24 months. ${ }^{47}$ Whether these results signify a mitigation of the effects of expectation, truly waning clinical effects of pallidotomy, or advancing disease is not easy to assess. These studies, however, place the benefits of unilateral pallidotomy in the range of $20 \%$ to $30 \%$ based on motor UPDRS score at 2 years after surgery. Finally, nonrandomized (open-label) trials place the pallidotomy effect in the same range.

Hayward et al. ${ }^{48}$ noted that "results from a single RCT with a small sample size are not necessarily more convincing than consistent results with high precision from a large number of high-quality trials of nonrandomized design conducted in a variety of places and times." We recently reviewed the published cases of pallidotomy. ${ }^{49}$ Outcomes at 6 to 12 months at 22 international sites reporting 528 patients yielded UPDRS motor 'off' scores that improved $31.3 \%$ (weighted average), with individual sites reporting $11 \%$ to $65 \%$ improvement. At 18 to 36 months, the response in 97 patients was maintained at $33.5 \%$ benefit (18\% to $77 \%$ change at each center). At more than 40 months, the benefit in 47 patients declined to $18.3 \%$. It can be concluded that a $20 \%$ to $30 \%$ decrease in motor 'off' scores is a fairly reliable number, with the larger number probably reflecting patient bias, and that less reliable measures of long-term benefit indicate some decrease over time. Overall, tremor $(-69 \%)$, rigidity $(-49 \%)$ and bradykinesia $(-36 \%)$ improve after unilateral pallidotomy. ${ }^{49}$ However, axial symptoms, postural stability and gait disturbance fare less well $(-19 \%$, $-17 \%$, and $-26 \%$ respectively). Improvements in 'off' period freezing, postural instability, and gait seen at 6 months were absent by 24 months. ${ }^{33}$
The two $\mathrm{RCTs}^{32,33}$ and the open-label series ${ }^{49}$ demonstrate the most striking improvements in drug-induced dyskinesia contralaterally at both early and late time points. Ipsilateral effects on dyskinesia are present early and late in some ${ }^{33}$ but not all series, possibly related to the size or location of the lesions. We showed that lesion location is an independent predictor of clinical outcome (using blinded assessments of both). ${ }^{50,51}$ Overall, total UPDRS scores decreased the most with centrally located lesions. More anteromedially placed lesions were more effective on rigidity, centrally placed lesions on akinesia, and posterolateral lesions on tremor, whereas reduction in contralateral dyskinesia was independent of lesion location. Persistent tremor and dyskinesia reduction at 24 months reported by Samii et al. ${ }^{46}$ in the absence of other benefits might reflect posterolaterally located lesions, as was also seen by Hariz and Bergenheim ${ }^{52}$ in their 10 year follow-up of 13 of Laitinen's patients with posterolateral lesions. In patients with akinesia, rigidity, and tremor, more centrally located lesions may be the most effective. Although the anteromedial region preferentially affects rigidity, it is also associated with decreased cognitive performance ${ }^{53}$ and thus should be avoided.

The argument has often been advanced that axial features require bilateral surgery. Several reports of small numbers of patients document variable benefits from bilateral pallidotomy done either simultaneously or staged. Although improvements in 'off' time and motor 'off' scores may be seen in some studies, ${ }^{54-56}$ benefits to gait and postural stability have not been reliably found; in some series, gait and postural stability worsened. ${ }^{49}$ Most importantly, most series found an increased incidence of unacceptable adverse effects involving speech, drooling, other corticobulbar functioning, and gait, as well as cognitive dysfunction. Although bilateral pallidotomy is effective, the marginal gains of performing the second side are to be considered against the increased incidence of adverse effects and in the end, especially considering the availability of alternatives, cannot be recommended.

\section{Is posteroventral pallidotomy a safe therapy for PD?}

Among the touted advantages of DBS over ablative surgery, reversibility is at the top. But why would you want to reverse a pallidotomy? Only if the result had been intolerable adverse effects. How often and how severe are the adverse effects from pallidotomy, and how do they compare to DBS? From a literature survey covering 1510 patients, Alkhani and Lozano ${ }^{57}$ found a rate of persistent ( $>3$ months) adverse effects of $14.3 \%$, including symptomatic infarction or hemorrhage (1.7\%), dysarthria $(1.6 \%)$, visual field defect $(1.5 \%)$, facial weakness $(1.3 \%)$, hypophonia $(1.3 \%)$, and dysphagia $(0.5 \%)$. These rates may be confounded by being derived 
mostly from retrospective data sets, and representing centers with varying technical proficiency with the operation, which may have counteracting effects.

Insight into the first factor comes from the review by de Bie et al., ${ }^{58}$ who separated trials into retrospective and prospective and found $6.4 \%$ persistent adverse effects (359 patients) in the historical set of series, but 13.8\% (334 patients) in the prospective set of series. In the latter, the following were found: dysarthria (3.6\%), visual field defect $(2.4 \%)$, facial weakness $(2.4 \%)$, hypophonia (1.2\%), dysphagia (2.4\%), personality changes (3.9\%), and hypersalivation (2.1\%). In most instances, the rates from the prospective series are higher than those shown by the Alkhani and Lozano ${ }^{57}$ analysis. The effects of technical issues on complications were assessed with respect to the use of microelectrode mapping, but the effect of location along the learning curve could not be assessed by either study. However, Vitek et al. ${ }^{59}$ noted improvement in their complication rate with experience. They had two symptomatic hemorrhages in their first 23 patients, and none in the next 137 patients; in their last 80 patients, no persistent neurological deficit was noted. This is indeed mirrored in their prospective $\mathrm{RCT},{ }^{33}$ in which no patients developed persistent deficits, and only one had a transient worsening of speech $(n=18)$.

Thus, unilateral pallidotomy is a relatively safe operation, compared with the benefits that can be expected. On its own merits, it is unlikely that modern pallidotomy would have been abandoned based on an excessive rate of adverse effects.

\section{Is DBS a safer and more effective therapy for PD?}

The reader is referred to the article on DBS for PD in this issue, by Limousin et al. ${ }^{60}$ Here we will address only the few comparison trials that have been published (Table 1). In 1998, Kumar et al. ${ }^{61}$ examined results in a retrospective review with unequal group sizes and follow-up times. Unilateral pallidotomy showed similar results to patients receiving either unilateral or bilateral GPi DBS in terms of 'off' motor responses, 'off' disability, and dyskinesia reduction. Patients receiving bilateral STN DBS had greater reduction in 'off' motor and disability scores, greater reduction in 'on' motor scores, but less dyskinesia reduction (at 3 months after DBS, perhaps prior to optimization of stimulation and medication). Merello et al. ${ }^{43}$ subsequently randomized patients to unilateral pallidotomy $(n=7)$ or unilateral GPi DBS $(n=6)$, but assessments were not blinded. Again follow-up was too short (3 months). There was no difference between the groups in 'off' motor UPDRS scores, which improved by $29.7 \%$ in the pallidotomy versus $28.8 \%$ in the GPi DBS group. Neither procedure improved gait disorder. Two patients in the pallidotomy group developed transient dysphagia, and one patient in the DBS group developed transient paresis; there were no differences in neuropsychological outcome between groups. A recent study by Jiménez et al. ${ }^{62}$ yielded similar results in a prospective but nonrandomized, nonblinded trial. Clinical improvement was essentially the same in the unilateral pallidotomy and unilateral GPi DBS groups in 'off' motor UPDRS scores, medication reductions $(31 \%)$ were equal, and one of nine patients experienced persistent hypophonia in the pallidotomy group.

Pallidotomy has never been directly compared with unilateral STN DBS. However, unilateral STN DBS was found to yield similar effects to unilateral GPi DBS on tests of contralateral fine motor function. ${ }^{63}$ Unilateral STN DBS improved 'off' motor UPDRS scores by $26 \%,{ }^{64} 31 \%,{ }^{65}$ and $37 \%,{ }^{66}$ remarkably similar to the results with unilateral pallidotomy. Samii et al ${ }^{67}$ found an improvement in 'off' motor UPDRS scores of $25 \%$ with unilateral STN DBS, increasing to $43 \%$ when the contralateral side was added, stressing that one of the advantages of DBS is that it can be performed bilaterally, but that the results are not simply twice as good as unilateral surgery because of axial as well as ipsilateral effects of unilateral STN DBS (as seen by others as well). Thus, it appears likely that the benefits of unilateral pallidotomy are similar to those of unilateral GPi or STN DBS, and the chief advantage of DBS is that it can be done bilaterally when necessary. Some even advocate a staged procedure in asymmetric patients, thus begging the question as to whether the first side should actually be a pallidotomy.

Unilateral pallidotomy was compared with bilateral STN DBS in single-blind (observer-blind) RCT, with the primary outcome measure being the motor UPDRS score change from baseline at 6 months. ${ }^{41}$ Significantly greater reduction in 'off' motor scores was found in the bilateral STN DBS group (48.6\%), compared with the pallidotomy group (20\%), but as already noted this small RCT may be confounded by patient bias in favor of bilateral STN DBS. Nevertheless, the $48.6 \%$ improvement in 'off' motor UPDRS scores was remarkably similar to the averaged results in a meta-analysis of openlabel bilateral STN studies $(52 \%),{ }^{68}$ and this is substantially greater than the open-label results with unilateral pallidotomy (31\%). ${ }^{49}$ Although I would argue that the true bilateral STN DBS effects would be $10 \%$ to $15 \%$ lower (i.e., $\sim 35 \%-40 \%$ improvement) were patient bias to be controlled in a double-blind trial (which has never been done), this would still be substantially better than the true unilateral pallidotomy effect seen in controlled studies in which bias is not in its favor $(\sim 20 \%-30 \%)$. Bilateral STN DBS is, therefore, superior in effectiveness to unilateral pallidotomy.

What is actually known about the results when stimulation is performed contralateral to a previous pallidotomy? Only a small number of case series address this issue. Most concern adding bilateral STN DBS to 
a previous pallidotomy, cases in which it is not clear whether the previous pallidotomy was particularly effective. In these situations, contralateral STN DBS may be deleterious, due to concerns regarding medication reductions in the context of the STN DBS that would adversely affect the pallidotomy side, for which medications generally cannot be reduced. ${ }^{69}$ Only two reports, comprising nine patients total, address adding a single GPi DBS contralateral to a pallidotomy. ${ }^{70,71}$ Blomstedt et al. ${ }^{70}$ reported the results of adding GPi DBS contralateral to pallidotomy in five patients, with motor 'off' UPDRS improved by $32.7 \%$ at last followup. However, this was an average of 22 months after the contralateral DBS, and 37 months after the initial pallidotomy, so it is impossible to compare the results of this small study to the acute results after a bilateral DBS implantation. We have a large cohort of patients who underwent GPi or STN DBS (randomly assigned) contralateral to a pallidotomy and evaluated in a prospective double-blind design, the results of which are currently being analyzed.

\section{Is there still a role for lesion therapy for PD?}

In sum, unilateral pallidotomy is an effective and safe procedure for the treatment of PD, yielding $20 \%$ to $30 \%$ decreases in 'off' motor UPDRS scores, with good contralateral benefits on tremor, akinesia, and rigidity, and excellent effects on dyskinesia and dystonia, but with minimal effects on axial features. Its effectiveness is similar to unilateral GPi DBS and unilateral STN DBS, and in experienced hands is close in safety of those procedures; however, bilateral pallidotomy is probably less safe than bilateral STN DBS, which (along with bilateral GPi DBS) is favored when there is bilateral and axial symptomatology, including 'off' period freezing. Unilateral pallidotomy therefore remains a viable surgical option that may be performed in certain scenarios, as follows.

1) When a patient does not want implanted hardware, and does not want to or cannot suitably participate in the extensive programming necessary with DBS. In this case, unilateral pallidotomy can be performed, but if the contralateral side should be necessary, we would only offer DBS. Other alternatives are now in clinical trials, including cell implantation (e.g., retinal pigment epithelial cells, tested as Spheramine [Titan Pharmaceuticals, South San Francisco, CA]) and gene therapy.

2) When a patient is medically unable to undergo general anesthesia. Pallidotomy is an alternative because it does not require the anesthesia currently associated with tunneling of the extension cable. The only other alternative that does not require anesthesia (excepting cell transplantation or gene therapy) is gamma knife pallidotomy, but although this has been pursued in some centers, the safety profile may not be acceptable, ${ }^{72,73}$ even compared with gamma knife thalamotomy. For patients unable to tolerate awake surgery, pallidotomy is not the best option, because monitoring for adverse effects during lesion generation is critical. In the cases in which I have performed pallidotomy in sleeping patients, I have attempted to wake them for the lesioning component, although not always successfully (e.g., in a 7-yearold patient, and in a patient with severe chorea from Huntington's disease; personal observations).

3) When DBS is not available. Whether because of expense $^{74}$ or the logistics of programming, DBS is not universally available, and therefore in many places pallidotomy continues to be frequently performed. Many of the recent reports on pallidotomy have come from China, Taiwan, South Korea, Hungary, Poland, and Brazil. ${ }^{75-81}$ Given the expense of hardware and hardware-related complications, and the labor intensiveness of programming and the great distance that may need to be traveled to programming centers, it is difficult to envision this situation changing soon.

\section{SUBTHALAMIC LESIONS FOR PD}

Another alternative to DBS and pallidotomy that may garner increased attention in the coming years is stereotactic ablation of the subthalamic nucleus. Based on experimental work in nonhuman primates ${ }^{82,83}$ (which laid the foundation for STN DBS), several small trials of subthalamic nucleotomy were performed, both unilaterally and bilaterally. To date, the literature contains references to 78 patients who have undergone 96 subthalamic nucleus lesions (18 bilaterally) (Table 2). ${ }^{84-88}$ Unilateral STN ablation improved contralateral symptoms in all of the studies. However, when reported, 'off' total motor scores improved by only $19 \%^{86}$ to $30 \%^{87}$ at 6 months, persisting at 12 to 24 months. The studies are confounded by the implantation of contralateral STN DBS (although it was switched off before clinical testing) in a subset of patients. Transient dyskinesia or hemiballism was seen in a fraction of the patients (a few of whom required either DBS or thalamotomy to treat it), but one patient died from aspiration pneumonia secondary to severe, persistent hemiballism. ${ }^{87}$

Bilateral STN ablation had more robust effects. Alvarez et al. ${ }^{84,85}$ reported a $50 \%$ decrease in 'off' total motor UPDRS scores 3 to 4 years after bilateral surgery in 18 patients, 11 of whom had their lesions contemporaneously. Postoperatively, medications were significantly reduced. Postoperative chorea was severe in only three patients, although it resolved by 6 months, and was mild and short-lasting in 13. Three patients in whom the lesions were large experienced severe dysarthria. No patient experienced cognitive decline. 
TABLE 2. Outcomes of Subthalamic Nucleotomy for Parkinson's Disease

\begin{tabular}{|c|c|c|c|c|c|}
\hline \multirow[b]{2}{*}{ Author, Date } & \multirow[b]{2}{*}{ Follow-up } & \multicolumn{2}{|c|}{$\begin{array}{l}\text { STN } \\
\text { Lesion }\end{array}$} & \multirow{2}{*}{$\begin{array}{l}\text { Change in 'Off' } \\
\text { UPDRS Motor } \\
\text { Score, } \%\end{array}$} & \multirow[b]{2}{*}{ Adverse Effects } \\
\hline & & Uni & $\mathrm{Bi}$ & & \\
\hline Alvarez et al. ${ }^{85}$ (2005) & $3-4 \mathrm{yr}$ & & 18 & 49.5 & $\begin{array}{l}\text { Transient mild dyskinesia (13); } 3 \text { severe } \\
\text { chorea (3-6 mo); } 3 \text { severe persistent } \\
\text { dysarthria }\end{array}$ \\
\hline Patel et al. ${ }^{86}$ (2003) & $12 \mathrm{mo}$ & $21 *$ & & 15.5 & $\begin{array}{l}1 \text { dyskinesia, treated with ipsilateral H2/ZI } \\
\text { DBS; no speech }\end{array}$ \\
\hline Su et al. ${ }^{87}(2003)$ & $12 \mathrm{mo}$ & $12^{\dagger}$ & & 32.0 & $\begin{array}{l}\text { Two transient dyskinesia/HB; } 1 \mathrm{HB} \rightarrow \text { death } \\
\text { due to aspiration pneumonia; no speech }\end{array}$ \\
\hline Vilela Filho et al. ${ }^{88}$ (2002) & 9-22.5 mo & $21^{\ddagger}$ & & $\mathrm{n} / \mathrm{r}$ & $\begin{array}{l}1 \text { chorea; } 1 \text { HB: both resolved with Vop/ } \\
\text { Vim lesion }\end{array}$ \\
\hline
\end{tabular}

$\mathrm{Bi}=$ bilateral DBS = deep brain stimulation; $\mathrm{HB}=$ hemiballism; $\mathrm{n} / \mathrm{r}=$ not reported; $\mathrm{STN}=$ subthalamic nucleus; Uni $=$ unilateral; Vim $=$ ventral intermediate thalamic nucleus; Vop $=$ ventralis oralis posterior thalamic nucleus.

*17/21 patients had tremor-dominant PD; 4 had bilateral PD and had contralateral STN DBS (which was off for clinical evaluations); 19/21 lesions extended into Forel H2/ZI (one of those whose lesion did not so extend developed dyskinesia, which abated with ipsilateral H2/ZI DBS).

${ }^{\dagger} / 12$ patients had previous or concurrent contralateral STN DBS (which was off for clinical evaluations).

$\$ 8 / 21$ patients underwent ipsilateral Vop/ZI thalamotomy.

Thus, STN ablation appears to be an alternative to DBS that may be relatively safe to perform bilaterally when DBS is not an option. However, whether unilateral subthalamic nucleotomy is more effective than unilateral pallidotomy, and whether bilateral subthalamic nucleotomy is safer than bilateral pallidotomy is not possible to deduce from the literature. The question could well be addressed by a controlled trial in centers where DBS is relatively unavailable.

\section{WHAT HAPPENED TO PALLIDOTOMY FOR DYSTONIA?}

In the mid-20th century, dystonia was treated more often with thalamotomy than pallidotomy. ${ }^{89}$ Similarly to pallidotomy for PD, with dystonia the period between the 1970s and the 1990s saw few publications on pallidotomy, although during this same period there continued to be approximately one article per year on thalamotomy. With the resurgence of pallidotomy, its success in treating dyskinesia and dystonia in PD led to two early reports of striking benefits in primary generalized dystonia patients. ${ }^{90,91}$ There followed a surge of reports on the success of pallidotomy in primary dystonia, and more limited success in secondary dystonia, publication peaking in 1998..$^{92-112}$ Coincidentally, the first modern publication on pallidotomy for dystonia ${ }^{90}$ came in the same year (1996) as the seminal paper on Vim DBS for tremor, ${ }^{4}$ and very quickly DBS began to replace pallidotomy for dystonia (see further in the article by Ostrem and Starr ${ }^{113}$ on DBS for dystonia, in this issue).

\section{Is posteroventral pallidotomy an effective and safe therapy for dystonia?}

Because of the rapid replacement of pallidotomy with pallidal DBS, there are no controlled studies of pallidotomy for dystonia. The published series contain small numbers of patients, and standardized measures were not always used, the 1990s being early in the era of evidence-based medicine in surgery. Between 1996 and 2007, published reports documented 29 patients who underwent pallidotomy for primary dystonia and 40 who received pallidotomy for secondary dystonias (Table 3), ${ }^{92-112}$ but a much smaller sample underwent evaluation with standardized measures. Twelve patients with primary dystonia experienced a $61 \% \pm$ $20 \%$ decrease in the Burke-Fahn-Marsden Dystonia Rating Scale (BFMDRS) movement subscale at 3 to 6 months after bilateral pallidotomy (Table 4 ), whereas there was only a $20 \%$ average decrease $(0 \%-71 \%)$ in patients with secondary dystonia after unilateral or bilateral pallidotomy (Table 5).

Longer-term results are less well catalogued. The largest series, ${ }^{111}$ from Houston, Texas, reported that five of eight patients with primary dystonia experienced marked improvement on the Global Outcome Scale at long-term follow-up (mean, 10.6 months), whereas two of six secondary dystonia patients experienced marked improvement long-term (13.8 months). One cautionary report concerned a patient who had a good response on his penultimate follow-up exam, but deteriorated by 96 months to a level worse than preoperatively. ${ }^{93}$

We have performed bilateral pallidotomy (simultaneous or staged) on seven patients with primary gen- 
TABLE 3. Outcomes of Pallidotomy for Dystonia

\begin{tabular}{|c|c|c|c|c|c|c|}
\hline Study & Type & $n$ & Follow-up & Outcome Scales & Qualitative & $\begin{array}{l}\text { Complications } \\
\text { or Comments }\end{array}$ \\
\hline Iacono et al. ${ }^{90}(1996)$ & Pri & 1 & $24 \mathrm{mo}$ & none & Excellent & \\
\hline Lozano et al. ${ }^{91}$ (1997) & Pri & 1 & $3 \mathrm{mo}$ & BFMDRS(M) & Excellent & \\
\hline Weetman et al. ${ }^{110}$ (1997) & $\mathrm{Sec}$ & 1 & $8 \mathrm{mo}$ & BFMDRS(M,D) & Good & $\begin{array}{l}\text { transient } \\
\text { dysphagia }\end{array}$ \\
\hline Vitek et al. $^{109}(1998)$ & Pri & 3 & $1 \mathrm{wk}-2 \mathrm{mo}$ & BFMDRS(M,D) & Good-excellent & \\
\hline Ondo et al. ${ }^{105}$ (1998)* & Pri & 4 & $16-56 \mathrm{mo}$ & BFMDRS(M) & Good-excellent & \\
\hline & $\mathrm{Sec}$ & 4 & $9-51 \mathrm{mo}$ & BFMDRS(M) & Poor-good & \\
\hline Iacono et al. ${ }^{12}$ (1998) & Pri & 3 & $2 \mathrm{wk}-12 \mathrm{mo}$ & none & Moderate-good & \\
\hline & $\mathrm{Sec}$ & 1 & $6 \mathrm{mo}$ & none & Poor & \\
\hline Lai et al. ${ }^{100}$ (1999) & Pri & 1 & $2 \mathrm{wk}$ & FIM & Good & \\
\hline Justesen et al. ${ }^{99}$ (1999) & Sec & 1 & $6 \mathrm{mo}$ & none & Moderate & $\begin{array}{l}\text { Hallervorden- } \\
\text { Spatz }\end{array}$ \\
\hline Cubo et al. ${ }^{95}(2000)$ & $\mathrm{Sec}$ & 1 & $3 \mathrm{mo}$ & BFMDRS(M) & Poor & $\begin{array}{l}\text { HC; stupor, } \\
\text { death }\end{array}$ \\
\hline Lin et al. ${ }^{102,104}(1999,2001)$ & $\mathrm{Sec}$ & 18 & $12 \mathrm{mo}^{\dagger}$ & BFMDRS(M,D) & Poor & 7 transient \\
\hline Teive et al. ${ }^{108}$ (2001) & Pri & 4 & $6 \mathrm{mo}$ & BFMDRS(M) & Good-excellent & $\begin{array}{l}1 \text { transient } \\
\text { hemiparesis }\end{array}$ \\
\hline Choi et al. ${ }^{94}$ (2003) & $\begin{array}{l}\text { Sec } \\
\text { Sec }\end{array}$ & $\begin{array}{l}1 \\
1\end{array}$ & $\begin{array}{l}6 \mathrm{mo} \\
6 \mathrm{mo}\end{array}$ & $\begin{array}{l}\text { BFMDRS(M) } \\
\text { none }\end{array}$ & $\begin{array}{l}\text { Poor } \\
\text { Excellent }\end{array}$ & $\begin{array}{l}\text { poststroke } \\
\text { chorea }\end{array}$ \\
\hline Eltahawy et al. ${ }^{96}$ (2004) & $\begin{array}{l}\text { Pri } \\
\text { Sec }\end{array}$ & $\begin{array}{l}4^{\ddagger} \\
3\end{array}$ & $\begin{array}{l}6 \mathrm{mo} \\
6 \mathrm{mo}\end{array}$ & $\begin{array}{l}\text { BFMDRS(M) } \\
\text { BFMDRS(M) }\end{array}$ & $\begin{array}{l}\text { Moderate-excellent } \\
\text { Poor }\end{array}$ & 2 speech \\
\hline Ford $^{97}$ (2004) & Pri + Sec & $5+1$ & $8-42$ mo & BFMDRS(M) & Poor & \\
\hline Rakocevic et al. ${ }^{106}$ (2004) & $\mathrm{Sec}$ & 1 & $24 \mathrm{mo}$ & none & Moderate & $\begin{array}{l}\text { gaze } \\
\text { preference }\end{array}$ \\
\hline Imer et al. ${ }^{98}(2005)$ & $\begin{array}{l}\text { Pri } \\
\text { Sec }\end{array}$ & $\begin{array}{l}2 \\
6\end{array}$ & & $\begin{array}{l}\text { BFMDRS(M,D) } \\
\text { BFMDRS(M) }\end{array}$ & $\begin{array}{l}\text { Mixed } \\
\text { Mixed }\end{array}$ & \\
\hline Alkhani and Bohlega ${ }^{92}$ (2006) & $\mathrm{Sec}$ & 24 & & DRS & Excellent & \\
\hline Cersosimo et al ${ }^{93}$ (2008) & Pri & 2 & $14-19$ & BFMDRS(M,D) & Excellent & $\begin{array}{r}\text { permanent } \\
\text { anarthria }\end{array}$ \\
\hline
\end{tabular}

BFMDRS $(\mathrm{M}, \mathrm{D})=$ Burke-Fahn-Marsden Dystonia Rating Scale (Movement, Disability); DRS = Dystonia Rating Scale; FIM = Functional Independence Measure; GOS = Global Outcome Scale; HC = Huntington's chorea; Pri = primary; Sec = secondary.

*These same pallidotomy cases were subsequently reported by Yoshor et al. ${ }^{111}$ (2004), but with no additional data relevant to this table.

${ }^{\dagger}$ Mean follow-up. ${ }^{\ddagger}$ Patient 1 in this series is the same as reported by Lozano et al. ${ }^{91}$ (1997).

eralized dystonia with good to excellent results in five patients and fair results in two, but with four of the patients requiring repeat pallidotomy (to make the lesion larger) on one side. One patient has persistent sialorrhea. One of the patients had a previous GPi DBS on one side, but lead breakage two times (exemplifying one of the problems with DBS in the current configuration for patients with dystonia) led to its removal and a subsequent pallidotomy with equally good results. Two other patients had left pallidotomy and right GPi DBS, both with excellent results, but one had persistent speech difficulties after the pallidotomy. Follow-up BFMDRS scores from our patients are being compiled.

\section{Is DBS a safer and more effective treatment for dystonia?}

In contrast to pallidotomy, GPi DBS has been evaluated in two randomized, sham-stimulation controlled, double-blind trials in 22 and 40 primary dystonia patients. Decreases in BFMDRS of $39 \%$ to $47 \%$ at 3 months were found in stimulated patients, versus 5\% to $25 \%$ in the sham-stimulated patients. ${ }^{114-116}$ In open-label stimulation, patients showed marked improvements in the BFMDRS at 6 to 12 months (45\%$51 \%)^{114,115}$ and 3 years $(58 \%)^{116}$ after surgery. In approximately $10 \%$ of patients, stimulation was stopped because of lack of effect, stimulation-related side effects, infection, technical problems, or lead breakage. Dysarthria occurred in $10 \%$, as well.

Thus, it appears that results with bilateral GPi DBS are in the same range as those experienced with bilateral pallidotomy in open-label trials (45\% to $58 \%$ decrease versus $61 \%$, respectively), although the former findings are derived from RCTs with control for both observer and patient bias, as opposed to the open-label retrospective series on pallidotomy. Complications appear to be infrequent in both groups. However, although the DBS patients experience infection and hardware complications not present in those undergoing pallidotomy, adverse effects when experi- 
TABLE 4. Outcomes of Bilateral Pallidotomy for Primary Dystonia

\begin{tabular}{|c|c|c|c|c|c|}
\hline \multirow[b]{2}{*}{ Study and Dystonia Subtype } & \multirow[b]{2}{*}{ Age at Surgery, yr } & \multirow[b]{2}{*}{ Follow-up, mo } & \multicolumn{2}{|c|}{ BFMDRS(M) } & \multirow[b]{2}{*}{$\%$ Decrease } \\
\hline & & & Pre & Post & \\
\hline \multicolumn{6}{|l|}{ Ondo et al. ${ }^{105}$ (1998) } \\
\hline Idiopathic & 51.0 & $3 *$ & 57 & 9 & 84 \\
\hline Dyt1 + & 9.0 & $3 *$ & 26 & 13 & 50 \\
\hline Dyt $1+$ & 14.0 & $3 *$ & 50 & 17 & 66 \\
\hline Dyt1+ & 13.0 & $3 *$ & 48 & 17 & 65 \\
\hline \multicolumn{6}{|l|}{ Teive et al. ${ }^{108}(2001)$} \\
\hline Dyt1 - & 16.0 & 6 & 60 & 18 & 70 \\
\hline Idiopathic & 5.0 & 6 & 50 & 28 & 44 \\
\hline Idiopathic & 23.0 & 6 & 48 & 4 & 92 \\
\hline Idiopathic & 21.0 & 6 & 28 & 12 & 57 \\
\hline \multicolumn{6}{|l|}{ Eltahawy et al. $^{96}$ (2004) } \\
\hline Dyt1+ & 10.0 & 6 & 75 & 25 & 67 \\
\hline Dyt $1+$ & 12.0 & 6 & 71 & 38 & 46 \\
\hline Dyt1+ & 15.0 & 6 & 53 & 13 & 75 \\
\hline Dyt1 - & 16.0 & 6 & 49 & 40 & 18 \\
\hline Mean $\pm \mathrm{SD}^{\dagger}$ & 17.1 & 5 & $51 \pm 14$ & 2011 & 6120 \\
\hline \multicolumn{6}{|l|}{ Cersosimo et al. ${ }^{93}$ (2008) } \\
\hline Dyt1+ & 19.0 & $96^{\dagger}$ & 108 & 21 & 81 \\
\hline Dyt $1+$ & 14.0 & $96^{\dagger}$ & 42 & 50 & -19 \\
\hline
\end{tabular}

Included are all cases that had BFMDRS results at defined time points of at least 3 months follow-up. All had bilateral pallidotomy; no cases of unilateral pallidotomy fulfilled these criteria. Idiopathic cases did not have reported Dyt1 status.

BFMDRS(M) = Burke-Fahn-Marsden Dystonia Rating Scale (Movement).

*Only the mean follow-up time was reported; therefore, some cases had less than 3 months follow-up.

†The cases with 96-month follow-up are excluded from the mean calculation, because one of the cases had good outcome at 6 months, but deteriorated at the 96-month time point.

enced are in most instances reversible. An argument can be made that bilateral GPi DBS is neither more effective nor safer than bilateral pallidotomy for primary dystonia, and both are equally ineffective for secondary dystonia.

\section{Is there still a role for lesion therapy for dystonia?}

Although not established with class 1 evidence, multiple series show that pallidotomy is effective and safe. Unfortunately, pallidotomy for dystonia was relaunched after pallidotomy for PD and therefore the procedure was not widely tested in trials before it was supplanted by DBS. As with pallidotomy for PD, however, it is being pursued for dystonia in places where DBS is less available, ${ }^{92-94,98,104,110}$ and more publications can be expected accordingly.

Neither pallidotomy nor DBS seems to have a wide role in secondary dystonia, although some patients do seem to benefit from both, which may be etiologyspecific (e.g., tardive dyskinesia). ${ }^{17-120}$ For primary dystonia, bilateral pallidotomy has a much greater role than it does for PD, insofar as most patients have bilateral and axial symptoms, and bilateral surgery may be better tolerated than in patients with PD. Moreover, because patients are younger, and often require relatively high current with DBS, there is a greater risk with DBS in terms of multiple battery changes, and dystonia itself in the context of an in- complete response may lead to a higher incidence of lead fracture or dislodgement. Thus, even in the developed world, bilateral pallidotomy may continue to have a role in some patients. We have patients who were offered DBS but chose bilateral pallidotomy for these reasons, with good results.

\section{ANSWERS TO THE TASKER QUESTION: WHAT HAPPENED TO POSTEROVENTRAL PALLIDOTOMY?}

There is no doubt that, where DBS is widely available, pallidotomy is rarely performed for PD or dystonia. Was pallidotomy abandoned because it was not effective? Although class 1 studies with appropriate control of bias are not available, the preponderance of uncontrolled studies do establish the high likelihood, if not certainty, that unilateral pallidotomy is both an effective and safe treatment for both PD and dystonia. On the one hand, these uncontrolled studies likely overestimate the benefits of pallidotomy; on the other, many of these studies were performed at the leading edge of the learning curve on pallidotomy, so it is possible they underestimate the benefits. The foregoing analysis suggests that unilateral pallidotomy is approximately as effective as either unilateral GPi or STN DBS.

Was pallidotomy abandoned because it was not safe? In experienced hands, the safety of unilateral pal- 
TABLE 5. Outcomes of Unilateral or Bilateral Pallidotomy for Secondary Dystonias

\begin{tabular}{|c|c|c|c|c|c|c|c|}
\hline \multirow[b]{2}{*}{ Study and Dystonia Subtype } & \multirow[b]{2}{*}{$n$} & \multicolumn{2}{|c|}{ Surgery } & \multirow[b]{2}{*}{ Follow-up, mo } & \multicolumn{2}{|c|}{$\operatorname{BFMDRS}(\mathrm{M})$} & \multirow[b]{2}{*}{$\%$ Decrease } \\
\hline & & Age & Side & & Pre & Post & \\
\hline \multicolumn{8}{|l|}{ Weetman et al. ${ }^{110}$ (1997) } \\
\hline Tardive dystonia & 1 & 31 & $\mathrm{Bi}$ & 8 & 76 & 22 & 71 \\
\hline \multicolumn{8}{|l|}{ Ondo et al. ${ }^{105}$ (1998) } \\
\hline Traumatic & 1 & 56 & Uni & 3 & 34 & 13 & 62 \\
\hline Traumatic & 1 & 18 & $\mathrm{Bi}$ & 3 & 56 & 46 & 18 \\
\hline Hypoxic & 1 & 16 & $\mathrm{Bi}$ & 3 & 59 & 17 & 71 \\
\hline Peripheral trauma & 1 & 20 & Uni & 3 & 23 & 6 & 74 \\
\hline \multicolumn{8}{|l|}{ Cubo et al. ${ }^{95}$ (2000) } \\
\hline Huntington's disease & 1 & 13 & $\mathrm{Bi}$ & 3 & 56 & 49 & 13 \\
\hline \multicolumn{8}{|l|}{ Lin et al. ${ }^{002,104}(1999,2001)$} \\
\hline Cerebral palsy & 8 & & $\mathrm{Bi}$ & & & & \\
\hline Hypoxic & 6 & & $\mathrm{Bi}$ & & & & \\
\hline Carbon monoxide & 2 & 26 & $\mathrm{Bi}$ & 12 & 58 & 50 & 13 \\
\hline Postinfectious & 1 & & $\mathrm{Bi}$ & & & & \\
\hline Postencephalitis & 1 & & $\mathrm{Bi}$ & & & & \\
\hline \multicolumn{8}{|l|}{ Teive et al. ${ }^{108}(2001)$} \\
\hline Traumatic & 1 & 37 & $\mathrm{Bi}$ & 6 & 51 & 51 & 0 \\
\hline Postencephalitis & 1 & 22 & Uni & 6 & 28 & 28 & 0 \\
\hline Poststroke & 1 & 30 & Uni & 6 & 25 & 25 & 0 \\
\hline Glutaric aciduria & 1 & 10 & $\mathrm{Bi}$ & 6 & 113 & 99 & 12 \\
\hline Weighted average ${ }^{\dagger}$ & & 30 & & 9 & 56 & 45 & 20 \\
\hline
\end{tabular}

Included are cases of secondary dystonia with BFMDS(M) scores at 3 months or greater $(N=28)$.

BFMDRS $(\mathrm{M})=$ Burke-Fahn-Marsden Dystonia Rating Scale (Movement); Bi = bilateral; $\mathrm{N}=$ number of patients; Uni $=$ unilateral.

${ }^{\dagger}$ Weighted average takes account of mean data from Lin et al. ${ }^{102,104}$

lidotomy is similar to that of unilateral DBS, without the hardware-related and programming issues. However, the safety of bilateral pallidotomy has not been established, compared with bilateral DBS (especially STN DBS), and therein lies the chief advantage of DBS over pallidotomy. The major limitation of bilateral DBS, however, is its cost in terms of resources. When unilateral symptoms are present, pallidotomy could still have an important role in the treatment of PD and dystonia (and similarly thalamotomy for tremor, but that falls beyond the scope of the present review). This is certainly true where DBS is not available or feasible, as in developing countries. Where bilateral symptoms are present in PD, bilateral pallidotomy cannot—-without further study — be recommended. In this case, unilateral pallidotomy with contralateral GPi DBS is preferred, or bilateral STN or GPi DBS. In generalized dystonia, however, there may be a greater role for bilateral pallidotomy because of increased safety and the disadvantage, with the present hardware, of DBS in dystonia (higher current usage; greater number of pulse generator changes; risk of hardware complications).

So-What happened to pallidotomy? In the end, although pallidotomy still has a role in the treatment of movement disorders, it has essentially been replaced by a safer, albeit more expensive, therapy.

\section{REFERENCES}

1. Tasker RR, Siqueira J, Hawrylyshyn P, Organ LW. What happened to VIM thalamotomy for Parkinson's disease? Appl Neurophysiol 1983;46:68-83.

2. Laitinen LV, Bergenheim AT, Hariz MI. Ventroposterolateral pallidotomy can abolish all parkinsonian symptoms. Stereotact Funct Neurosurg 1992;58:14-21.

3. Hariz MI. From functional neurosurgery to "interventional" neurology: survey of publications on thalamotomy, pallidotomy, and deep brain stimulation for Parkinson's disease from 1966 to 2001. Mov Disord 2003;18:845-853.

4. Benabid AL, Pollak P, Gao D, et al. Chronic electrical stimulation of the ventralis intermedius nucleus of the thalamus as a treatment of movement disorders. J Neurosurg 1996;84:203-214.

5. van de Warrenburg BP, Bhatia KP, Quinn NP. Pisa syndrome after unilateral pallidotomy in Parkinson's disease: an unrecognised, delayed adverse event? J Neurol Neurosurg Psychiatry 2007;78:329-330.

6. York MK, Lai EC, Jankovic J, et al. Short and long-term motor and cognitive outcome of staged bilateral pallidotomy: a retrospective analysis. Acta Neurochir (Wien) 2007;149:857-866; discussion 866.

7. Meyers R. Surgical procedure for postencephalitic tremor, with notes on the physiology of the premotor fibres. Arch Neurol Psychiatry 1940;44:455-459.

8. Meyers R. Historical background and personal experiences in the surgical relief of hyperkinesia and hypertony. In: Fields WS, editor. Pathogenesis and treatment of parkinsonism; sixth annual scientific meeting of the Houston Neurological Society, Texas Medical Center, Houston, Texas. Springfield, IL: Charles C. Thomas, 1958:229-270.

9. Guridi J, Lozano AM. A brief history of pallidotomy. Neurosurgery 1997;41:1169-1180; discussion 1180-1183.

10. Narabayashi H, Okuma T. Procaine oil blocking of the globus 
pallidus for the treatment of rigidity and tremor of parkinsonism. Psychiatr Neurol Japonica 1953;56:471-495.

11. Cooper IS. Ligation of the anterior choroidal artery for involuntary movements; parkinsonism. Psychiatr Q 1953;27:317-319.

12. Spiegel E, Wycis H, Marks M, Lee AJ. Stereotaxic apparatus for operations on the human brain. Science 1947;106:349-350.

13. Cooper IS. Surgical treatment of parkinsonism. Annu Rev Med 1965;16:309-330.

14. Cooper IS, Bravo G. Chemopallidectomy and chemothalamectomy. J Neurosurg 1958;15:244-250.

15. Hassler R. The pathological and pathophysiological basis of tremor and parkinsonism. In: Proceedings of the 2nd International Congress of Neuropathology, Excerpta Medica Foundation. Amsterdam: Excerpta Medica 1955;1:29-40.

16. Hassler R, Riechert T, Mundinger F, Umbach W, Ganglberger JA. Physiological observations in stereotaxic operations in extrapyramidal motor disturbances. Brain 1960;83:337-350.

17. Laitinen LV. Brain targets in surgery for Parkinson's disease: results of a survey of neurosurgeons. J Neurosurg 1985;62:349351.

18. Laitinen LV. Pallidotomy for Parkinson's disease. Neurosurg Clin N Am 1995;6:105-112.

19. Svennilson E, Torvik A, Lowe R, Leksell L. Treatment of parkinsonism by stereotactic thermolesions in the pallidal region: a clinical evaluation of 81 cases. Acta Psychiatr Scand 1960;35: $358-377$.

20. Laitinen LV, Bergenheim AT, Hariz MI. Leksell's posteroventral pallidotomy in the treatment of Parkinson's disease. J Neurosurg 1992;76:53-61.

21. Alexander GE, DeLong MR, Strick PL. Parallel organization of functionally segregated circuits linking basal ganglia and cortex. Annu Rev Neurosci 1986;9:357-381.

22. DeLong MR, Crutcher MD, Georgopoulos AP. Primate globus pallidus and subthalamic nucleus: functional organization. J Neurophysiol 1985;53:530-543.

23. Albin RL, Young AB, Penney JB. The functional anatomy of basal ganglia disorders. Trends Neurosci 1989;12:366-375.

24. Miller WC, DeLong MR. Parkinsonian symptomatology: an anatomical and physiological analysis. Ann N Y Acad Sci 1988; 515:287-302.

25. Rychetnik L, Frommer M, Hawe P, Shiell A. Criteria for evaluating evidence on public health interventions. J Epidemiol Community Health 2002;56:119-127.

26. Freeman TB, Vawter DE, Leaverton PE, et al. Use of placebo surgery in controlled trials of a cellular-based therapy for Parkinson's disease. N Engl J Med 1999;341:988-992.

27. Freed CR, Breeze RE, Fahn S. Placebo surgery in trials of therapy for Parkinson's disease. N Engl J Med 2000;342:353-354; author reply $354-355$.

28. Freed CR, Greene PE, Breeze RE, et al. Transplantation of embryonic dopamine neurons for severe Parkinson's disease. N Engl J Med 2001;344:710-719.

29. Olanow CW, Goetz CG, Kordower JH, et al. A double-blind controlled trial of bilateral fetal nigral transplantation in Parkinson's disease. Ann Neurol 2003;54:403-414.

30. Bakay RA. Metaanalysis, pallidotomy, and microelectrodes. J Neurosurg 2002;97:1253-1256; author reply 1256.

31. Palur RS, Berk C, Schulzer M, Honey CR. A metaanalysis comparing the results of pallidotomy performed using microelectrode recording or macroelectrode stimulation. J Neurosurg 2002;96: $1058-1062$.

32. de Bie RM, de Haan RJ, Nijssen PC, et al. Unilateral pallidotomy in Parkinson's disease: a randomised, single-blind, multicentre trial. Lancet 1999;354:1665-1669.

33. Vitek JL, Bakay RA, Freeman A, et al. Randomized trial of pallidotomy versus medical therapy for Parkinson's disease. Ann Neurol 2003;53:558-569.

34. Lozano AM, Lang AE, Galvez-Jimenez N, et al. Effect of GPi pallidotomy on motor function in Parkinson's disease [Erratum in: Lancet 1996;348:1108].Lancet 1995;346:1383-1387.

35. Gross RE, Lozano AM, Lang AE, Tasker RR, Hutchison WD, Dostrovsky JO. The effects of pallidotomy on Parkinson's dis- ease: study design and assessment techniques. Acta Neurochir Suppl 1997;68:24-28.

36. Ondo WG, Jankovic J, Lai EC, et al. Assessment of motor function after stereotactic pallidotomy. Neurology 1998;50:266-270.

37. de la Fuente-Fernández R, Ruth TJ, Sossi V, Schulzer M, Calne DB, Stoessl AJ. Expectation and dopamine release: mechanism of the placebo effect in Parkinson's disease. Science 2001;293:1164-1166.

38. Clark PI, Leaverton PE. Scientific and ethical issues in the use of placebo controls in clinical trials. Annu Rev Public Health 1994; $15: 19-38$.

39. Lacritz LH, Cullum CM, Frol AB, Dewey RB Jr, Giller CA Neuropsychological outcome following unilateral stereotactic pallidotomy in intractable Parkinson's disease. Brain Cogn 2000; 42:364-378.

40. McRae C, Cherin E, Yamazaki TG, et al. Effects of perceived treatment on quality of life and medical outcomes in a doubleblind placebo surgery trial [Erratum in: Arch Gen Psychiatry 2004;61:627]. Arch Gen Psychiatry 2004;61:412-420.

41. Esselink RA, de Bie RM, de Haan RJ, et al. Unilateral pallidotomy versus bilateral subthalamic nucleus stimulation in PD: a randomized trial. Neurology 2004;62:201-207.

42. Esselink RA, de Bie RM, de Haan RJ, et al. Unilateral pallidotomy versus bilateral subthalamic nucleus stimulation in Parkinson's disease: one year follow-up of a randomised observer-blind multi centre trial. Acta Neurochir (Wien) 2006;148: 1247-1255; discussion 1255

43. Merello M, Nouzeilles MI, Kuzis G, et al. Unilateral radiofrequency lesion versus electrostimulation of posteroventral pallidum: a prospective randomized comparison. Mov Disord 1999; 14:50-56.

44. Merello M, Nouzeilles MI, Cammarota A, Betti O, Leiguarda R. Comparison of 1-year follow-up evaluations of patients with indication for pallidotomy who did not undergo surgery versus patients with Parkinson's disease who did undergo pallidotomy: a case control study. Neurosurgery 1999;44:461-467; discussion 467-468.

45. Kishore A, Turnbull IM, Snow BJ, et al. Efficacy, stability and predictors of outcome of pallidotomy for Parkinson's disease: six-month follow-up with additional 1-year observations. Brain 1997;120:729-737.

46. Samii A, Turnbull IM, Kishore A, et al. Reassessment of unilateral pallidotomy in Parkinson's disease: a 2-year follow-up study. Brain 1999;122:417-425.

47. Fine J, Duff J, Chen R, et al. Long-term follow-up of unilateral pallidotomy in advanced Parkinson's disease. N Engl J Med 2000;342:1708-1714.

48. Hayward RS, Wilson MC, Tunis SR, Bass EB, Guyatt G. Users' guides to the medical literature. VIII. How to use clinical practice guidelines. A. Are the recommendations valid? The EvidenceBased Medicine Working Group. JAMA 1995;274:570-574.

49. Gross RE, Lozano AM. Stereotactic pallidotomy and thalamotomy. In: Factor SA, Weiner WJ, editors. Parkinson's disease: diagnosis and clinical management. 2nd ed. New York: Demos Medical Publishing, 2008. p. 699-723.

50. Gross RE, Lombardi WJ, Hutchison WD, et al. Variability in lesion location after microelectrode-guided pallidotomy for Parkinson's disease: anatomical, physiological, and technical factors that determine lesion distribution. J Neurosurg 1999;90:468-477.

51. Gross RE, Lombardi WJ, Lang AE, et al. Relationship of lesion location to clinical outcome following microelectrode-guided pallidotomy for Parkinson's disease. Brain 1999;122:405-416.

52. Hariz MI, Bergenheim AT. A 10-year follow-up review of patients who underwent Leksell's posteroventral pallidotomy for Parkinson disease. J Neurosurg 2001;94:552-558.

53. Lombardi WJ, Gross RE, Trepanier LL, Lang AE, Lozano AM, Saint-Cyr JA. Relationship of lesion location to cognitive outcome following microelectrode-guided pallidotomy for Parkinson's disease: support for the existence of cognitive circuits in the human pallidum. Brain 2000;123:746-758.

54. Intemann PM, Masterman D, Subramanian I, et al. Staged bilateral pallidotomy for treatment of Parkinson disease. J Neurosurg 2001;94:437-444. 
55. Parkin SG, Gregory RP, Scott R, et al. Unilateral and bilateral pallidotomy for idiopathic Parkinson's disease: a case series of 115 patients. Mov Disord 2002;17:682-692.

56. Counihan TJ, Shinobu LA, Eskandar EN, Cosgrove GR, Penney JB Jr. Outcomes following staged bilateral pallidotomy in advanced Parkinson's disease. Neurology 2001;56:799-802.

57. Alkhani A, Lozano AM. Pallidotomy for Parkinson disease: a review of contemporary literature. J Neurosurg 2001;94:43-49.

58. de Bie RM, de Haan RJ, Schuurman PR, Esselink RA, Bosch DA, Speelman JD. Morbidity and mortality following pallidotomy in Parkinson's disease: a systematic review. Neurology 2002;58: 1008-1012.

59. Vitek JL, Bakay RA, Hashimoto T, et al. Microelectrode-guided pallidotomy: technical approach and its application in medically intractable Parkinson's disease. J Neurosurg 1998;88:1027-1043.

60. Limousin P, Martinez-Torres I. Deep brain stimulation for Parkinson's disease. Neurotherapeutics 2008;5:000-000 (this issue).

61. Kumar R, Lozano AM, Montgomery E, Lang AE. Pallidotomy and deep brain stimulation of the pallidum and subthalamic nucleus in advanced Parkinson's disease. Mov Disord 1998;13 Suppl 1:73-82.

62. Jiménez F, Velasco F, Carrillo-Ruiz JD, et al. Comparative evaluation of the effects of unilateral lesion versus electrical stimulation of the globus pallidus internus in advanced Parkinson's disease. Stereotact Funct Neurosurg 2006;84:64-71.

63. Nakamura K, Christine CW, Starr PA, Marks WJ Jr. Effects of unilateral subthalamic and pallidal deep brain stimulation on fine motor functions in Parkinson's disease. Mov Disord 2007;22: 619-626.

64. Germano IM, Gracies JM, Weisz DJ, Tse W, Koller WC, Olanow CW. Unilateral stimulation of the subthalamic nucleus in Parkinson disease: a double-blind 12-month evaluation study. J Neurosurg 2004;101:36-42.

65. Slowinski JL, Putzke JD, Uitti RJ, et al. Unilateral deep brain stimulation of the subthalamic nucleus for Parkinson disease. J Neurosurg 2007;106:626-632.

66. Chung SJ, Jeon SR, Kim SR, Sung YH, Lee MC. Bilateral effects of unilateral subthalamic nucleus deep brain stimulation in advanced Parkinson's disease. Eur Neurol 2006;56:127-132.

67. Samii A, Kelly VE, Slimp JC, Shumway-Cook A, Goodkin R. Staged unilateral versus bilateral subthalamic nucleus stimulator implantation in Parkinson disease. Mov Disord 2007;22:14761481.

68. Kleiner-Fisman G, Herzog J, Fisman DN, et al. Subthalamic nucleus deep brain stimulation: summary and meta-analysis of outcomes. Mov Disord 2006;21 Suppl 14:S290-S304.

69. Merello M. Subthalamic stimulation contralateral to a previous pallidotomy: an erroneous indication? Mov Disord 1999;14:890.

70. Blomstedt P, Hariz GM, Hariz MI. Pallidotomy versus pallidal stimulation. Parkinsonism Relat Disord 2006;12:296-301.

71. Gálvez-Jiménez N, Lozano A, Tasker R, Duff J, Hutchison W, Lang AE. Pallidal stimulation in Parkinson's disease patients with a prior unilateral pallidotomy. Can J Neurol Sci 1998;25:300-305.

72. Duma CM. Movement disorder radiosurgery: planning, physics and complication avoidance. Prog Neurol Surg 2007;20: 249-266.

73. Okun MS, Stover NP, Subramanian T, et al. Complications of gamma knife surgery for Parkinson disease. Arch Neurol 2001; 58:1995-2002.

74. McIntosh E, Gray A, Aziz T. Estimating the costs of surgical innovations: the case for subthalamic nucleus stimulation in the treatment of advanced Parkinson's disease. Mov Disord 2003;18: 993-999.

75. Chung SJ, Hong SH, Kim SR, Lee MC, Jeon SR. Efficacy and safety of simultaneous bilateral pallidotomy in advanced Parkinson's disease. Eur Neurol 2006;56:113-118.

76. Liu X, Wang H, Qian Z, Yang T, Gu Y. Method of localization of microelectrode in the globus pallidus during pallidotomy for Parkinson's disease [In Chinese]. Sheng Wu Yi Xue Gong Cheng Xue Za Zhi 2007;24:488-491.

77. Llumiguano C, Doczi T, Baths I. Microelectrode guided stereotactic pallidotomy and pallido-thalamotomy for treatment of Par- kinson's disease [In Spanish]. Neurocirugia (Astur) 2006; $17: 420-432$.

78. Mourão LF, Aguiar PM, Ferraz FA, Behlau MS, Ferraz HB Acoustic voice assessment in Parkinson's disease patients submitted to posteroventral pallidotomy. Arq Neuropsiquiatr 2005; 63:20-25.

79. Olzak M, Laskowska I, Jelonek J, et al. Psychomotor and executive functioning after unilateral posteroventral pallidotomy in patients with Parkinson's disease. J Neurol Sci 2006;248:97-103.

80. Tsai CH, Chang FC, Lu CS, et al. Pallidotomy effect on the cortical excitability in patients with severe Parkinson's disease. Mov Disord 2005;20:463-470.

81. Yen CP, Wu SJ, Su YF, Kwan AL, Howng SL, Shih PY. Unilateral stereotactic posteroventral globus pallidus internus pallidotomy for Parkinson's disease: surgical techniques and 2-year follow-up. Kaohsiung J Med Sci 2005;21:1-8.

82. Bergman H, Wichmann T, DeLong MR. Reversal of experimental parkinsonism by lesions of the subthalamic nucleus. Science 1990;249:1436-1438.

83. Aziz TZ, Peggs D, Sambrook MA, Crossman AR. Lesion of the subthalamic nucleus for the alleviation of 1-methyl-4-phenyl1,2,3,6-tetrahydropyridine (MPTP)-induced parkinsonism in the primate. Mov Disord 1991;6:288-292.

84. Alvarez L, Macias R, Guridi J, et al. Dorsal subthalamotomy for Parkinson's disease. Mov Disord 2001;16:72-78.

85. Alvarez L, Macias R, Lopez G, et al. Bilateral subthalamotomy in Parkinson's disease: initial and long-term response. Brain 2005; 128:570-583.

86. Patel NK, Heywood P, O'Sullivan K, McCarter R, Love S, Gill $\mathrm{SS}$. Unilateral subthalamotomy in the treatment of Parkinson's disease. Brain 2003;126:1136-1145.

87. Su PC, Tseng HM, Liu HM, Yen RF, Liou HH. Treatment of advanced Parkinson's disease by subthalamotomy: one-year results. Mov Disord 2003;18:531-538.

88. Vilela Filho O, da Silva DJ. Unilateral subthalamic nucleus lesioning: a safe and effective treatment for Parkinson's disease. Arq Neuropsiquiatr 2002;60:935-948.

89. Krack P, Vercueil L. Review of the functional surgical treatment of dystonia. Eur J Neurol 2001;8:389-399.

90. Iacono RP, Kuniyoshi SM, Lonser RR, Maeda G, Inae AM, Ashwal S. Simultaneous bilateral pallidoansotomy for idiopathic dystonia musculorum deformans. Pediatr Neurol 1996;14: 145-148.

91. Lozano AM, Kumar R, Gross RE, et al. Globus pallidus internus pallidotomy for generalized dystonia. Mov Disord 1997;12: 865-870.

92. Alkhani A, Bohlega S. Unilateral pallidotomy for hemidystonia. Mov Disord 2006;21:852-855.

93. Cersosimo MG, Raina GB, Piedimonte F, Antico J, Graff P, Micheli FE. Pallidal surgery for the treatment of primary generalized dystonia: long-term follow-up. Clin Neurol Neurosurg 2008;110:145-150.

94. Choi SJ, Lee SW, Kim MC, et al. Posteroventral pallidotomy in medically intractable postapoplectic monochorea: case report. Surg Neurol 2003;59:486-490; discussion 490.

95. Cubo E, Shannon KM, Penn RD, Kroin JS. Internal globus pallidotomy in dystonia secondary to Huntington's disease. Mov Disord 2000;15:1248-1251.

96. Eltahawy HA, Saint-Cyr J, Giladi N, Lang AE, Lozano AM. Primary dystonia is more responsive than secondary dystonia to pallidal interventions: outcome after pallidotomy or pallidal deep brain stimulation. Neurosurgery 2004;54:613-619; discussion 619-621.

97. Ford B. Pallidotomy for generalized dystonia. Adv Neurol 2004; 94:287-299.

98. Imerz M, Ozeren B, Karadereler S, et al. Destructive stereotactic surgery for treatment of dystonia. Surg Neurol 2005;64 Suppl 2:S89-S94; discussion S94-85.

99. Justesen CR, Penn RD, Kroin JS, Egel RT. Stereotactic pallidotomy in a child with Hallervorden-Spatz disease: case report. J Neurosurg 1999;90:551-554.

100. Lai T, Lai JM, Grossman RG. Functional recovery after bilateral 
pallidotomy for the treatment of early-onset primary generalized dystonia. Arch Phys Med Rehabil 1999;80:1340-1342.

101. Lin JJ, Lin GY, Shih C, Lin SZ, Chang DC, Lee CC. Benefit of bilateral pallidotomy in the treatment of generalized dystonia: case report. J Neurosurg 1999;90:974-976.

102. Lin JJ, Lin SZ, Chang DC. Pallidotomy and generalized dystonia. Mov Disord 1999;14:1057-1059.

103. Lin JJ, Lin SZ, Lin GY, Chang DC, Lee CC. Application of bilateral sequential pallidotomy to treat a patient with generalized dystonia. Eur Neurol 1998;40:108-110.

104. Lin JJ, Lin SZ, Lin GY, Chang DC, Lee CC. Treatment of intractable generalized dystonia by bilateral posteroventral pallidotomy: one-year results. Zhonghua Yi Xue Za Zhi (Taipei) 2001;64:231-238.

105. Ondo WG, Desaloms JM, Jankovic J, Grossman RG. Pallidotomy for generalized dystonia. Mov Disord 1998;13:693-698.

106. Rakocevic G, Lyons KE, Wilkinson SB, Overman JW, Pahwa R. Bilateral pallidotomy for severe dystonia in an 18-month-old child with glutaric aciduria. Stereotact Funct Neurosurg 2004;82: $80-83$.

107. Teive HA, Munhoz RP, Souza MM, et al. Status dystonicus: study of five cases. Arq Neuropsiquiatr 2005;63:26-29.

108. Teive HA, Sá DS, Grande CV, Antoniuk A, Werneck LC. Bilateral pallidotomy for generalized dystonia. Arq Neuropsiquiatr 2001;59:353-357.

109. Vitek JL, Zhang J, Evatt M, et al. GPi pallidotomy for dystonia: clinical outcome and neuronal activity. Adv Neurol 1998;78:211219.

110. Weetman J, Anderson IM, Gregory RP, Gill SS. Bilateral posteroventral pallidotomy for severe antipsychotic induced tardive dyskinesia and dystonia. J Neurol Neurosurg Psychiatry 1997;63:554-556.
111. Yoshor D, Hamilton WJ, Ondo W, Jankovic J, Grossman RG. Comparison of thalamotomy and pallidotomy for the treatment of dystonia. Neurosurgery 2001;48:818-824; discussion 824-826.

112. Iacono RP, Kuniyoshi SM, Schoonenberg T. Experience with stereotactics for dystonia: case examples. Adv Neurol 1998;78: 221-226.

113. Ostrem JL, Starr PA. Treatment of dystonia with deep brain stimulation. Neurotherapeutics 2008;5:000-000 (this issue).

114. Kupsch A, Benecke R, Müller J, et al. Pallidal deep-brain stimulation in primary generalized or segmental dystonia. N Engl J Med 2006;355:1978-1990.

115. Vidailhet M, Vercueil L, Houeto JL, et al. Bilateral deep-brain stimulation of the globus pallidus in primary generalized dystonia. N Engl J Med 2005;352:459-467.

116. Vidailhet M, Vercueil L, Houeto JL, et al. Bilateral, pallidal, deep-brain stimulation in primary generalised dystonia: a prospective 3 year follow-up study. Lancet Neurol 2007;6:223229.

117. Eltahawy HA, Feinstein A, Khan F, Saint-Cyr J, Lang AE, Lozano AM. Bilateral globus pallidus internus deep brain stimulation in tardive dyskinesia: a case report. Mov Disord 2004;19: 969-972.

118. Franzini A, Marras C, Ferroli P, et al. Long-term high-frequency bilateral pallidal stimulation for neuroleptic-induced tardive dystonia: report of two cases. J Neurosurg 2005;102:721-725.

119. Trottenberg T, Volkmann J, Deuschl G, et al. Treatment of severe tardive dystonia with pallidal deep brain stimulation. Neurology 2005;64:344-346.

120. Zhang JG, Zhang K, Wang ZC. Deep brain stimulation in the treatment of tardive dystonia. Chin Med J (Engl) 2006;119:789-792. 